\title{
Breeding for improved welfare in pigs: a conceptual framework and its use in practice
}

\author{
E. Kanis ${ }^{1,4}+$, H. van den Belt ${ }^{2}$, A. F. Groen ${ }^{1}$, J. Schakel ${ }^{3}$ and K. H. de Greef ${ }^{4}$ \\ ${ }^{1}$ Wageningen University, Animal Breeding and Genetics Group, PO Box 338, 6700 AH Wageningen, The Netherlands \\ ${ }^{2}$ Wageningen University, Applied Philosophy Group, Hollandseweg 1, 6706 KN Wageningen, The Netherlands \\ ${ }^{3}$ Wageningen University, Rural Sociology Group, Hollandseweg 1, 6706 KN Wageningen, The Netherlands \\ ${ }^{4}$ Animal Sciences Group, PO Box 65, 8200 AB Lelystad, The Netherlands \\ † E-mail : Egbert.Kanis@wur.nl
}

\begin{abstract}
Welfare of animals can be defined as the kind of feelings the environmental conditions bring about in the animals. These feelings depend on the needs of the animals and their degree of satisfaction. Needs of animals, and so their welfare, are partly genetically determined. Therefore, welfare can be changed by breeding. The aim of this study was to investigate how welfare of pigs under modern intensive farm conditions can be improved by genetic selection, with emphasis on the precise definition of the breeding goal and determination of the animal characteristics on which selection can be based in practice.

The existing thermoregulation model was used to develop a conceptual framework that describes welfare of growing pigs and production sows with respect to each of their needs as a curvilinear function of the respective environmental conditions. The framework assumes that welfare in terms of feelings is reflected by the physiological and behavioural mechanisms the pig has to activate in order to cope with the various environmental conditions it encounters. Based on those physiological and behavioural responses to changing conditions, five welfare zones can be distinguished for each need. Breeding goals for welfare were defined in terms of the transition points between these welfare zones, such that future pigs would better cope with unfavourable or unfamiliar farming conditions, therewith quickening the domestication process, to some extent. However, as long as genetic parameters for these transition points are not available, more common welfare-related characteristics like temperament, stress resistance and robustness can be included in the breeding goal, as an alternative.

For selection among potential breeding candidates, transition points between welfare zones can be determined in sib tests, thereby also collecting the data for estimating genetic parameters. As a cheaper alternative, breeding candidates could be tested under hard conditions and selected on their coping success. In addition, various behavioural tests and operant conditioning tests (to test a pig's motivation to change its actual environment) can be carried out. Under common conditions on the farm, problems associated with coping (like incidences of diseases, injuries, and stereotypies) and/or other relevant traits (e.g. saliva cortisol levels, longevity and even production traits) should be recorded routinely and used as selection index information. Selection for improved welfare should lead to more tolerant pigs that are better able to cope with possible unfavourable farm conditions by a more efficient use of the adaptation mechanisms they already possess. It should, however, not result in lowering husbandry standards. More research is needed to assess genetic correlations among various welfare aspects and with production traits to prevent undesired side effects in future populations of pigs.
\end{abstract}

Keywords: adaptation, animal welfare, basic needs, genetic variation, pigs. 


\section{Introduction}

There is increasing concern about welfare of farm animals, both in society, in livestock production and in animal science. Several possible reasons can be identified:(1) increased (cost) efficiency of animal production which often has led to husbandry conditions that cause extra stress to the animals, (2) decreased capabilities of farm animals to cope with their environment, (3) an increased ethical consciousness regarding animal welfare, and (4) an increased availability of information about farm animal welfare. This paper addresses the second reason, the capabilities of animals to cope with their environment.

There is evidence that several welfare aspects have a genetic basis (Grandin and Deesing, 1998a; Faure and Mills, 1998) and that genetic selection for increased production can have negative side effects on animal welfare (Grandin and Deesing, 1998b; Rauw et al., 1998; Sandøe et al., 1999; Muir and Schinckel, 2002). This indicates that purposive selection for a better animal welfare, be it in combination with selection for production or not, could be successful. In literature some suggestions for improving animal welfare by genetic selection can be found (e.g. Schutz and Pajor (2001) in cattle, Scobie et al. (1999) in sheep, Muir (1996) and Jones and Hocking (1999) in poultry), but little seems yet to be done in practice. Indeed, selection for longevity, leg quality, conformation, disease resistance, absence of heritable defects, etc. could also improve pig welfare (Wilkie and Mallard, 1999; Yazdi et al., 2000), but their main aim is often economic benefit. Muir and Schinckel (2002) show the effectiveness of accounting for group effects in selection for body weight of Japanese quails, thereby decreasing competitive effects resulting in a decreased aggression and mortality. Selection for meat quality by means of the halothane test is probably the best example in pigs of breeding for an economic trait that resulted in better welfare (reduced stress susceptibility) as a side effect (e.g. Schaeffer et al., 1989; Geers et al., 1994). Still, to avoid stress during transport and in the slaughterhouse, Grandin and Deesing (1998b) suggest that geneticists should select pigs that are easy to handle and have a calm temperament.

Systematic selection for better animal welfare first requires clear and unambiguous definitions of traits involved in welfare. Next, it should be decided what the proper breeding goal traits are and which measurable traits could provide sufficient information about those breeding goal traits. To find the relevant traits, this study develops a conceptual framework that aims to give more insight into welfare of pigs as far as this is affected by the capabilities of pigs to cope with their environment. Such a framework should be helpful as a tool to facilitate breeding for better welfare of pigs.

\section{Welfare and needs}

Animal welfare is a complex concept, which is difficult to define operationally, and hence to evaluate empirically (Rowan, 1997). In the present study we consider animal welfare as similar to 'animal happiness' which can be seen as the balance between an animal's positive and negative emotions or feelings over a certain time period. Such emotions depend on the differences between the animal's needs and the extent to which those needs are currently satisfied. Usually the animal will activate and perform a (coping) programme to reduce these differences such that it feels better (Wiepkema, 1987). Each need and its degree of satisfaction may contribute differently to overall happiness or overall welfare.

Welfare of an animal is thus related to its efforts to cope with its environment (e.g. Broom, 1994) and to the degree to which it is conscious of those efforts. Coping efforts may be temporally necessary (e.g. a fight to establish the hierarchy) or continuous (e.g. to cope with a low environmental temperature) and may be successful or not. If certain efforts appear to be unsuccessful the animal may change its coping strategy (e.g. from trying to free itself from a tether to resignation and perhaps stereotypic chewing). The more and stronger coping efforts an animal has to perform and the lower their success rate, the more negative emotions are likely to arise and the worse its welfare is assumed to be.

The degree to which pigs kept in modern production systems can satisfy their needs depends on the levels of those needs, on the coping abilities of the pigs, on other animal factors, as well as on environmental factors. To give an example of an 'other animal factor': in order to satisfy its hunger (a need) a pig might have enough food at its disposal, but its restricted physical food intake capacity might preclude complete (chemical) saturation and thus complete satisfaction of this need. The farmer, providing food either ad libitum or in a restricted quantity, or other pigs in the same group eating the food, are examples of environmental factors.

In general, improving a pig's welfare could be based on decreasing the pig's needs (demands), increasing the efficiency of the response or coping programme to satisfy its needs (tools) and improving the environment (supplies). Pig breeding can only be directed to those components of the demands, tools 
and supplies that show genetic variation among animals.

As assumed in the foregoing, each animal has needs. The Scientific Veterinary Committee (1997) of the European Union defined a need as a requirement, which is a consequence of the biology of the animal, to obtain a particular resource or respond to a particular environmental or bodily stimulus. To assess overall welfare, Bracke et al. (1999) defined needs as the states of the animal's motivational systems, which specify the animal's proximate goals. For pigs, Bracke et al. (1999) listed the following needs, based on various sources: ingestion (including the need for food and water), rest, social contact, reproduction-related needs (sex, nest building and maternal care), kinesis, exploration (including exploration of novelty, foraging and play), body care, evacuation, thermal comfort, respiration, health (including no injuries or pain) and safety (including no danger and no aggression). In the present study this list of needs will be used as a starting point. It should be noted that needs are not just all-or-none traits that are fulfilled or not, but that they can be satisfied to various degrees, depending for example on the husbandry system.

We first take the need for thermal comfort as a basis to develop a general concept of pig welfare, which is then extended to other needs. Next we apply the concept to propose new traits that possibly could be used in breeding for better welfare of pigs.

\section{Maintaining body temperature}

A homeothermic animal has to maintain a constant deep body temperature. It therefore produces (metabolic) heat of which the surplus has to be transmitted to the environment. To avoid a too high or too low heat loss the animal requires the ambient temperature to be within a certain range. To cope with the varying ambient temperatures within that range it has various adaptation mechanisms. Following Mount (1979), we assume that pigs are able to maintain their deep body temperature within the ambient temperature range $\mathrm{C} 0$ to $\mathrm{C} 5$ (Figure 1), where the $\mathrm{C}$-values represent critical temperatures marking different thermoregulatory zones. The zone $\mathrm{C} 1$ to $\mathrm{C} 4$, in which metabolic heat production $(\mathrm{H})$ is independent of ambient temperature, is usually referred to as the thermoneutral zone (e.g. Verstegen and Close, 1994). In the zone C2 to C3 pigs regulate their heat loss unconsciously by vasoconstriction and vasodilatation. An ambient temperature above $\mathrm{C} 3$ will motivate pigs to search for additional cooling possibilities and perform the necessary cooling behaviour, for example lying on a cold floor or wetting of the skin. So C3 is a threshold above which pigs get motivated to perform adaptive behaviour. A further increase of ambient temperature from $\mathrm{C} 4$ to $\mathrm{C} 5$ results in a reduced food intake (e.g. Le Bellego et al., 2002) and additional physiological actions like active panting and sweating (although pigs hardly sweat) to get rid of the superfluous heat. Panting is, however, accompanied by extra heat production. Beyond C5 a pig's deep body temperature will increase and if this lasts too long, the pig will lose homeostasis and die. A decrease in ambient temperature from $\mathrm{C} 2$ to $\mathrm{C} 1$ will stimulate motivation to perform adaptive behaviour like huddling or finding a well-insulated place to lie on in order to maintain body temperature. If the temperature decreases further from $\mathrm{C} 1$ down to $\mathrm{C} 0$ the pig has to produce extra heat (e.g. by shivering) to compensate for the heat it loses to the environment. Ambient temperatures lower than $\mathrm{C} 0$ cannot be coped with, resulting in a declining body temperature, ultimately leading to death.

\section{Ambient temperature, thermal comfort and welfare}

We now assume a relationship between thermoregulation and (the feeling of) thermal comfort as a component of welfare. Because little and probably unconscious effort is necessary to cope with an ambient temperature varying between $\mathrm{C} 2$ and C3, within this zone thermal comfort is at its maximum. In the zones $\mathrm{C} 3$ to $\mathrm{C} 4$ and $\mathrm{C} 2$ to $\mathrm{C} 1$ pigs are probably conscious of the fact that they have to adapt their behaviour, and this is likely to be associated with somewhat negative emotions and thus with a lower thermal comfort and a lower contribution to animal

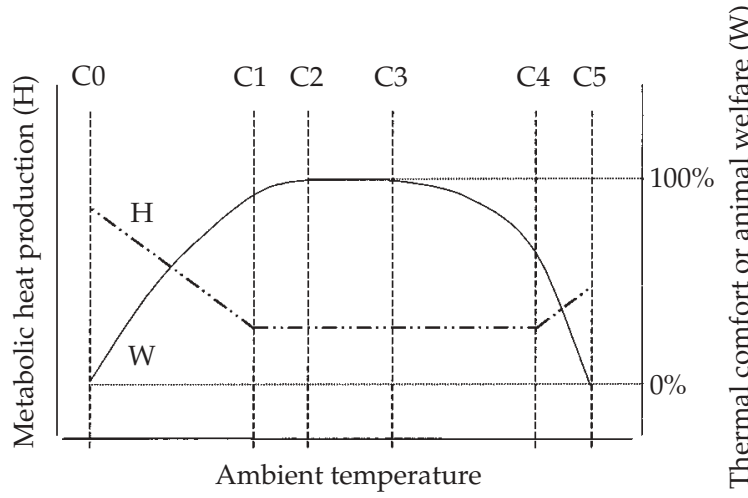

Figure 1 Diagrammatic representation (after Mount, 1979) of the relationship between ambient temperature and metabolic heat production $(\mathrm{H})$ and thier assumed influence on themal comfort as a component of animal welfare (W). Points $\mathrm{C} 0$ to $\mathrm{C} 5$ are critical ambient temperatures associated with different thermoregulatory mechanisms (see text for further explanation). 
welfare $(\mathrm{W})$. Such behavioural changes are, however, to be considered as normal adaptations for which the animal is well equipped. Temperatures outside the thermoneutral zone ( $\mathrm{C} 1$ to $\mathrm{C} 4)$ require extra and often aberrant metabolic and behavioural efforts to maintain a constant deep body temperature and are probably associated with strong negative emotions and thus a low animal welfare. Brown-Brandl et al. (2001), for example, showed that the increased respiration rate with a high ambient temperature is the first sign of heat stress in pigs.

Figure 1 represents the effects of ambient temperature on metabolic heat production $(\mathrm{H})$ and on assumed thermal comfort (W) for a given pig, keeping all environmental factors except ambient temperature at a normal and constant level. This model in its general form probably holds for all pigs under various ambient temperatures. However, the levels of heat production and thermal comfort (the curves in Figure 1) and the positions of $\mathrm{C} 0$ to $\mathrm{C} 5$ are age and environment specific. Older pigs, for example, usually have more backfat insulating the body than younger ones and have, therefore, lower $\mathrm{C}$-values (in particular lower $\mathrm{C} 2, \mathrm{C} 1$ and $\mathrm{C} 0$ ). When housed individually, pigs cannot huddle, which results in a higher $\mathrm{C} 1$ than with group housing. Within age or weight groups and under given husbandry conditions, some animals may be more efficient in vasoconstriction or huddling behaviour than others and have, therefore, lower C2 and C1 values. Such animals are more tolerant or resistant to low temperatures since ambient temperature has to decline more before their welfare is being compromised. In cattle, with hot temperatures, between-animal variation in time spent in the shade is generally known (e.g. Mitlöhner et al., 2001). Such between-animal variation in degree and way of thermal adaptation may be a starting point for genetic selection. For example, the first pigs that start panting with increasing ambient temperatures or that have an increased body temperature or reduced food intake, probably have an impaired welfare under high temperatures and should not be selected as parents for the next generation if pigs are to be kept in hot climates.

\section{The concept fitted to other needs}

Because the effects of ambient temperature on animal metabolism and behaviour are well studied and described, the concept as visualized in Figure 1 is a useful model for dealing with animal welfare insofar as it depends on ambient temperature. Thermal comfort is, however, just one among the many needs that affect emotional status and, if not sufficiently satisfied, could compromise animal welfare. We propose to extend the thermal-comfort model to other needs of pigs as described by Bracke et al. (1999) and listed in Table 1a and b (which will be discussed in more detail later in this paper). Instead of ambient temperature, other environmental factors related to specific needs, which usually can be influenced by the farmer, are put on the horizontal axis with C-values marking zones of different contributions to welfare. For each need we assume a maximum welfare zone $\mathrm{C} 2$ to $\mathrm{C} 3$ in which no or just unconscious behavioural or physiological adaptation is needed to cope with variation in a particular environmental factor. In both reduced welfare zones $\mathrm{C} 2$ to $\mathrm{C} 1$ and $\mathrm{C} 3$ to $\mathrm{C} 4$, the animal uses additional and functional behavioural and/or physiological coping mechanisms. These are probably used consciously and may compromise the animal's welfare to some degree, but fall within a range of adaptations that can be considered as normal. The zone $\mathrm{C} 1$ to $\mathrm{C} 4$ can thus be looked upon as the acceptable welfare zone. Outside this zone, in the two minimum welfare zones $(\mathrm{C} 1$ to $\mathrm{C} 0$ and $\mathrm{C} 4$ to $\mathrm{C5)}$, the animal takes refuge in additional physiological and/or behavioural responses to cope with the unfavourable situation which are often inadequate and which should be considered as abnormal. This is in line with the theory proposed by Jensen and Toates (1997) saying that animals which cannot cope adequately with a situation by executing a relevant behaviour will enter a state of stress. Behavioural responses are considered more indicative of stress and impaired welfare than physiological responses (Jensen and Toates, 1997).

An example of an important physiological adaptation concerns the need for health, interpreted here as the need to avoid (close) contact with high numbers of harmful micro-organisms (Table 1). For this need, with the density of harmful microorganisms on the horizontal axis in Figure 1, zones $\mathrm{C} 2$ to $\mathrm{C} 1$ and $\mathrm{C} 1$ to $\mathrm{C} 0$ do not exist or coincide with the maximum welfare zone $\mathrm{C} 2$ to $\mathrm{C} 3$ in which the intact skin and mucous membranes are sufficient to prevent an animal from becoming sick. In zone C3 to $C 4$ various additional immunological reactions are necessary and sufficient, but in zone C4 to C5 the animal becomes ill which is often accompanied by fever, reduced activity and lower food intake. Although fever and sickness behaviour are certainly functional coping mechanisms, they are clear signs of a low welfare regarding this need for health.

So, in general, C1 and C4 mark those boundaries outwith which the animal cannot cope any more through its normal physiology and/or behaviour. Beyond these values additional physiological and behavioural responses occur that should be considered as abnormal, indicating an impaired 
welfare. In pigs, frequently observed examples of abnormal behaviour (e.g. Scientific Veterinary Committee, 1997), are tail and ear biting and various stereotypic behaviours. These often develop if the animal is severely or chronically frustrated and should be considered either as an utmost way of coping (e.g. Cronin et al., 1985) or as a result of unsuccessful coping (see Wechsler (1995) for a review on coping).

We assume curvilinear relationships between the values of each environmental factor on the horizontal axis and animal welfare, such that the contribution to welfare increasingly declines from its maximum if environmental conditions are deviating more from the zone $\mathrm{C} 2$ to $\mathrm{C} 3$. Because a unit to express feelings or welfare is not available, we express it as a percentage of its maximum. Lengths of zones and declines of welfare on both sides of the maximum welfare zone are generally different and arbitrarily drawn in Figure 1.

\section{The concept as a tool to improve welfare}

Although the concept based on Figure 1 was developed for use in pig breeding, it can also be used for optimizing the conditions in which pigs are kept. So, pig husbandry should aim at fulfilling pig needs such that preferably each pig reaches its maximum comfort zone for each need (i.e. offer an ambient temperature or evacuation possibilities between C2 and C3, given the pig's backfat thickness, its feeding level, the group size, the floor insulation, etc. ). Such environmental adaptations may, however, be costly and farmers may tend, therefore, to apply minimumcost solutions as long as production is not damaged. Therewith, animal welfare may be put at stake. Furthermore, even under good average farming conditions, pigs will encounter situations which may compromise their welfare, like moving to another pen, increased infection pressure, transport, slaughtering, etc.

By genetic selection, lower $\mathrm{C} 2, \mathrm{C} 1, \mathrm{C} 0$ and/or a higher $\mathrm{C} 3, \mathrm{C} 4, \mathrm{C} 5$ values could perhaps be realized, thus resulting in new generations of animals with an increased tolerance for e.g. low and/or high ambient temperatures or for few evacuation possibilities. Such animals are then able to maintain a higher level of welfare than 'unimproved' pigs over the same range of environmental conditions, or a similar level of welfare at more extreme (or unfamiliar) environments, which might have a beneficial effect on production costs.

To implement selection for welfare in pig breeding programmes, first of all it is important to know which C-values and for which needs are relevant or, in other words, which needs have significant impact on welfare but are often not fulfilled satisfactorily. These are often needs for which fulfilment results in higher net production costs, like needs for social contact, kinesis, exploration, etc. Secondly, it is important to know how heritable C-values for these needs are, because the higher the heritability, the better genetic selection works. There is evidence that many adaptation mechanisms have a heritable basis and can therefore be subject to effective natural or artificial selection (Newman, 1994). Benus et al. (1991) presented evidence for heritable variation in aggression and coping strategies in rodents. Regarding thermal comfort, Mount (1979, p. 128) lists a number of morphological, anatomical and functional adaptations in domestic animals that may be considered as breed or species characteristics and therefore (partly) heritable, like the presence of subcutaneous fat, large skin folds and humps. Within pig breeds the thickness of the backfat layer has a heritability of about 0.4 (e.g. Brandt and Täubert, 1998; Hermesch et al., 2000) which means that backfat thickness can successfully be changed by genetic selection. Brown-Brandl et al. (2001) suggest that increased protein deposition in newer genetic lines of pigs is associated with a higher heat production and thus with an increased susceptibility to heat stress. Favourable effects of selection for high immune response in pigs (Wilkie and Mallard, 1999), genetic variation in resistance to clinical and subclinical diseases (Henryon et al., 2001) and the finding by Hemsworth et al. (1990) that the heritability of the trait 'fear to humans' in gilts is about 0.37 are other indications that pig welfare can be changed by selection.

Because this is probably the first time that animal welfare aspects have been modelled in this way, no concrete information on relevance and heritabilities of C-values is available yet. Nevertheless, it seems worthwhile to consider the applicability of the presented concept for the various pig needs in order to ascertain if it is a valuable tool in further research on breeding for improved pig welfare.

\section{Specification of welfare characteristics for growing pigs and reproductive sows}

In Table $1 \mathrm{a}$ and $\mathrm{b}$, needs of growing pigs and additional needs of reproductive sows (Bracke et al., 1999) are briefly described and the related environmental factors on the horizontal axis are presented, along with relevant $\mathrm{C}$-values, coping mechanisms and possible selection directions. For some needs the environment cannot be expressed as a single technical parameter and should, therefore, 
Kanis, van den Belt, Groen, Schakel and de Greef

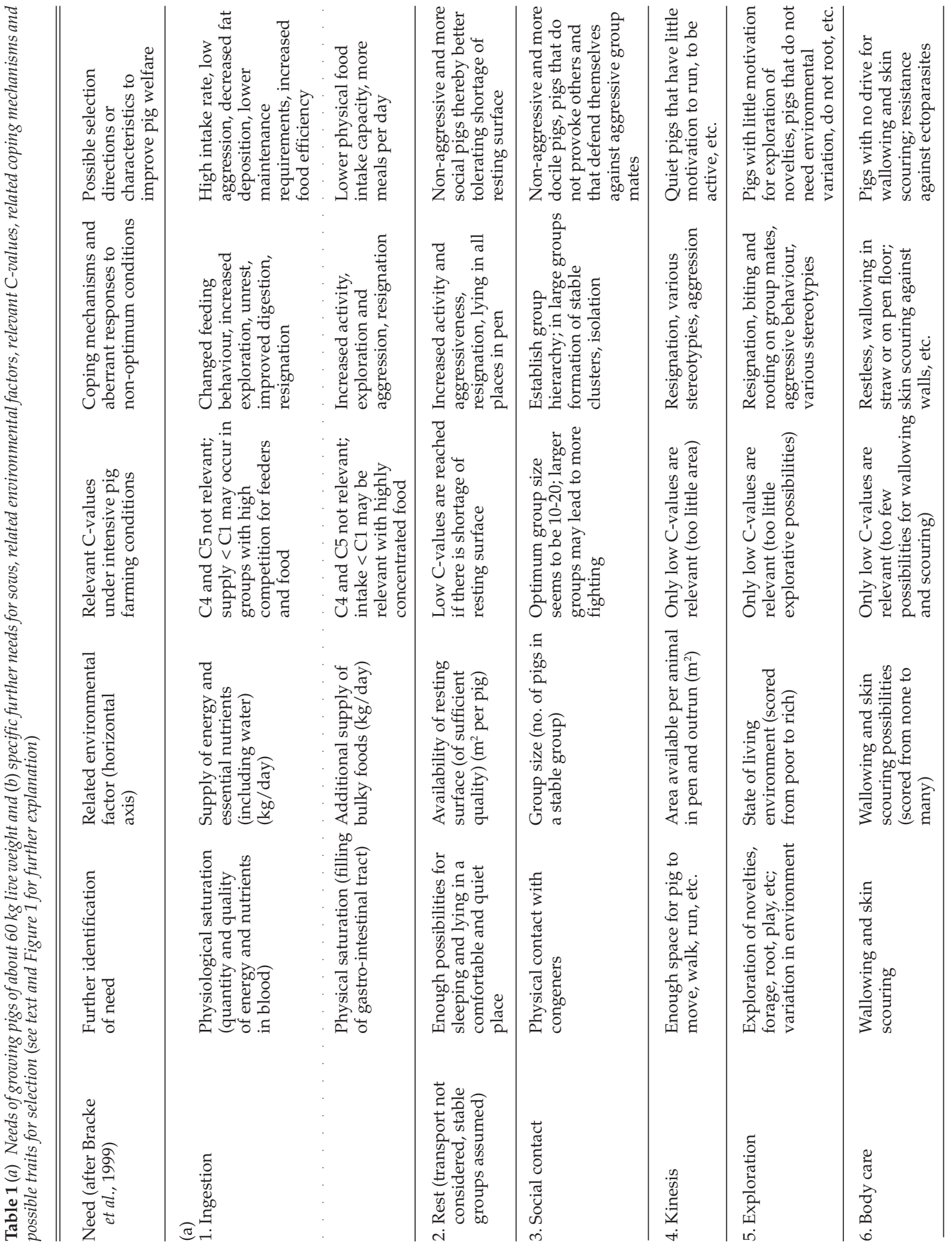


Animal welfare traits to breed for in pigs

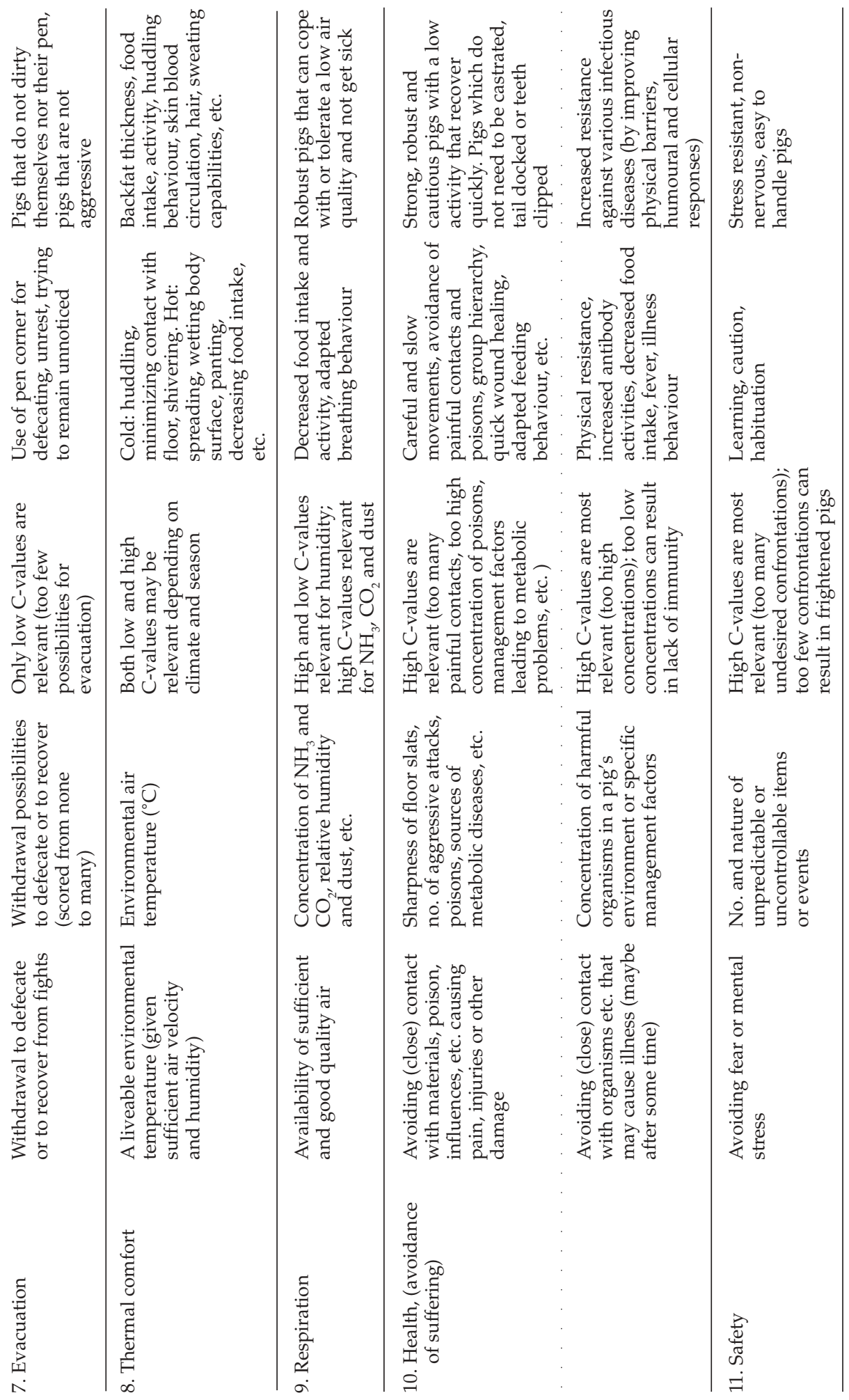




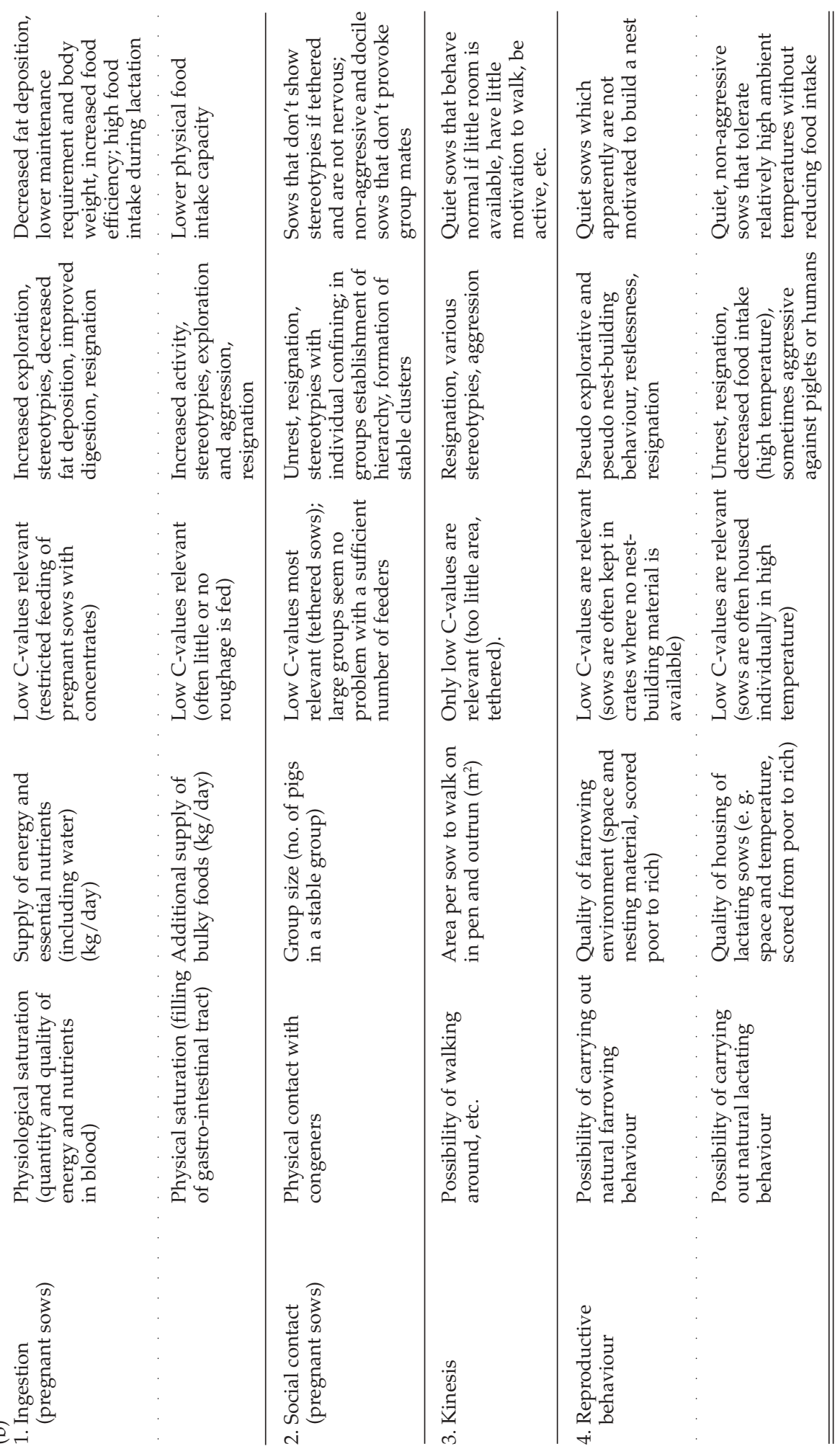


be scored as an index combining various environmental aspects. This has been done, for example, by Bracke (2001). Because effects of environment on welfare depend on age or weight of the pig, a growing pig of about $60 \mathrm{~kg}$ body weight is taken as a basis for needs of the growing pig, whereas a first-parity sow is taken as a basis for female reproductive needs. Further, prevailing farm conditions are assumed, excluding incidental activities like transport of animals, mixing of groups, etc.

Only those environmental conditions that lead to minimum pig welfare (zones $\mathrm{C} 4$ to $\mathrm{C} 5$ and $\mathrm{C} 1$ to $\mathrm{C} 0$ ) are considered. For most needs just one of these two zones is relevant because economic reasons often force farmers to keep their pigs at one end of the environmental scale. There is, for example, usually a restricted supply with food (or feeders), space, health care, etc. rather than a surplus. Moreover, even if there were a surplus compared with average farm conditions (e.g. an exploratively very rich environment, air without any $\mathrm{NH}_{3}$, etc.) this often does not lead to abnormal adaptive behaviour and a lower welfare.

Because housing and feeding of sows is quite different from that of growing pigs, needs specific to sows for ingestion, social contact and kinesis are included in Table $1 \mathrm{~b}$ as well as reproductive needs. As is often indicated in the literature (see Scientific Veterinary Committee (1997) for a review), intensively kept sows in particular are frequently confronted with conditions that compromise their welfare. This is especially the case for pregnant sows because they are often tethered with few possibilities for social contact. Moreover, pregnant sows get a limited amount of food because a high food intake during pregnancy would result in fatter sows at farrowing which sometimes results in fewer piglets born alive and a decreased milk production due to a lower food intake during lactation (Eissen et al., 2000). Group housing of pregnant sows and the provision of roughage improves their situation (Bergeron et al., 2000; Barnett et al., 2001). A few days before farrowing, sows are usually penned individually without supplying much material to fulfil their need to build a nest. Also during lactation, in order to prevent piglets from being crushed, most sows have little possibility of moving around unless they are kept outdoors in open huts.

\section{Practical implementation of the concept for breeding purposes \\ Breeding goal}

Breeding for improved welfare in pigs should start in practice with defining the breeding goal which in the following will be done at three levels. See Figure 2 (left side) for a visualization.

Overall welfare was defined as a weighted sum of the welfare levels per need which, theoretically, should thus be the traits to improve genetically. Because feelings cannot be measured, the required genetic (co)variances for welfare levels in terms of feelings will probably not become available. It is, therefore, not very practical to define a breeding goal as a weighted sum of feelings. An alternative is to use the weighted sum of relevant C-values for each
Possible levels of defining the breeding goal for welfare

Animal feelings (not practical)

C-values according to the concept in Figure 1 (changes in physiology and/or behaviour)

Grouped welfare

characteristics: temperament,

stress resistance, robustness
Possible levels of obtaining

information about welfare

C-values according to the concept in Figure 1 (changes in physiology and/or behaviour)

Operant conditioning tests, backtests, human approach tests, open door tests, etc.

Incidences of diseases, injuries and stereotypies, longevity, leg quality, ease of handling, hormone or antibody levels, etc.

Figure 2 Various levels for defining the breeding goal for welfare in pigs and possibilities of obtaining information on potential breeding animals. In both columns traits are presented in descending order regarding their supposed correlation with welfare. 
need (the environmental values that initiate a change in animal physiology or behaviour) as the breeding goal. As with the above, implementation of a breeding goal consisting of $\mathrm{C}$-values requires the availability of the accompanying genetic (co)variances. These parameters are not available either, but we believe that it is possible to estimate them in the future since the interest in doing largescale behavioural and physiological studies with pigs is increasing. As long as these parameters are not available, the breeding goal for welfare has to consist of traits we can readily observe. Based on the last column of Table $1 \mathrm{a}$ and $\mathrm{b}$, and on Grandin and Deesing (1998b) we may group animal welfare characteristics into three main traits:(1) temperament, which includes traits like aggressiveness, activity, curiosity and docility; (2) stress resistance, including fearfulness, nervousness and flexibility; (3) robustness, including bodily soundness and fitness, and disease resistance.

Apart from the fact that these three main traits cover various needs, it should be noted that they only reflect the size of an animal's needs, not the degree of satisfaction by the environment as C-values are intended to do. Individual scores for these three main welfare traits can be obtained by purposive observations. Several components of these traits can be tested and measured to estimate the relevant genetic (co)variances.

\section{Selection information}

Selection is based on information routinely recorded on the breeding candidates themselves and/or on relatives (usually indicated as index information or selection index traits). This implies recording of traits that are heritable and genetically correlated to the breeding goal traits.

It would be possible to measure C-values on the selection candidates (Figure 2), but since this implies stepwise and separate change of each relevant environmental factor (along the horizontal axis), this seems not practical for routine implementation by pig breeding organizations that usually test selection candidates under controlled environmental conditions. An alternative then is to measure Cvalues on relatives (e.g. sibs) of the selection candidates. This offers the opportunity to build up a data base on C-values and related traits that can be used to evaluate the concept and to estimate genetic and phenotypic (co)variances. Another option may be to develop measurements that are related to Cvalues. In central test stations, operant conditioning tests (OCTs) may be effective in obtaining information regarding the satisfaction of some needs (Figure 2). By OCTs potential breeding pigs or their sibs could be tested for their motivation to exchange a certain (bad or common) environmental condition for another (better) one (e.g. Bergeron et al., 2000). Pigs with the lowest motivation to change apparently feel best in their present environment (a negative correlation is assumed between motivation and welfare) and those pigs should then be selected for breeding purposes. Examples of other traits, correlated with C-values, that can be obtained with simple behavioural tests were recently published by van Erp-van der Kooij et al. (2002). They suggested that they could measure fear, activity and exploration or dominance in piglets by combining results from a 'backtest', a 'human approach test', an 'open door test' and a 'novel object test'. They found consistencies in behaviour of piglets over time and across situations.

There might, however, be (technical or economical) reasons or needs in which OCTs or other tests are not useful or applicable. For example, pigs probably cannot notice a difference between areas with high and low densities of harmful micro-organisms because the possible negative feelings (of fever, sickness) emerge only after some (incubation) time. In such cases problems with coping that are correlated with C-values (like incidences of stereotypies, diseases, leg problems and injuries) and/or other relevant traits (e.g. saliva cortisol levels, certain blood parameters, longevity and even production traits) could be recorded routinely (also in on-the-farm tests) and used as selection-index information. In current pig breeding programmes there might be already selection on some of these traits, but mainly for economic reasons. Muir and Schinckel (2002) proved in Japanese quails that selection for body weight while accounting for group effects can indirectly contribute to a decreased temper and increased robustness as expressed in reduced aggression and lower mortality. This shows that in some cases, just by better use of all available information in the selection procedure, welfare can already be improved, even if no real welfare characteristics are measured on the selection candidates.

\section{Discussion}

The concept

The aim of this study was to provide a conceptual framework that would be helpful as a tool to facilitate breeding for better welfare of pigs. We have taken animal feelings (emotions) as the basis for welfare because we consider welfare as similar to happiness which is an emotional status. Although we believe that (occurrence of) emotions has a heritable basis, their heritability can only be estimated indirectly. This was, for example, done by 
Hemsworth et al. (1990), who found a heritability of 0.37 in pre-pubertal gilts for what they interpreted as fear of humans, but which was measured as time to interact with the experimenter. Also based on estimation of various genetic parameters, Craig and Muir (1989), Kjaer and Sørensen (1997) and Kjaer et al. (2001) conclude that fear-related traits and feather pecking behaviour in White Leghorns should respond to selection. Schoenecker and Heller (2000) and Schwaibold and Pillay (2001) show a genetic basis for stereotypies in bank voles and striped mouse, respectively.

We have assumed that the degree of satisfaction for each need gives rise to specific feelings of (un)happiness and that such feelings are associated with, or have an observable effect on, pig behaviour and pig physiology. Changes in behaviour or physiology resulting from deteriorating environmental conditions are considered as indicators of (lower) welfare. The levels of the environmental factors at which such changes occur, depend on the tolerance of the animals and form the basis for genetic selection in the present concept. The concept should be further validated and tested for its usefulness. The approach, however, corresponds to societal concerns which are usually also based on (aberrant) behavioural or physiological responses of farm animals to the environment in which they are kept (Kanis et al., 2003). Therefore, breeding of pigs that can better cope with common farming conditions should be considered as a valuable contribution to animal welfare improvement which could diminish societal concerns at this point.

An existing and potentially useful concept, alternative to the concept presented in this paper but also referring to feelings, is 'motivation' (Dellmeier (1989)). Motivation approaches the 'animal preferences approach' of evaluating welfare mentioned by Barnett et al. (2001) and has been defined as 'forces acting on or within an organism to initiate and direct behaviour' and 'to explain differences in the intensity of behaviour' (Petrie (1986) cited by Dellmeier (1989)). If the degree of negative emotions is high the motivation to change the situation will also be high. Motivation is easy to comprehend, can be expressed on a quantitative scale (e.g. amount of work an animal is willing to perform) and includes a time element; the longer an animal is deprived from, for example, food the more it will be motivated to perform explorative behaviour. However, measuring motivation by OCTs can only be done for a restricted number of environmental situations (e.g. the present environment and one or a few choice alternatives) and does not reflect practical situations very well since pigs usually have no choice. Further, the motivation concept is only applicable for preferences of animals in the short term, i.e. an animal is not motivated to increase its immunity against some disease. Nevertheless it could be a practical option to breed for pigs which are less motivated to improve or change their situation, and are thus sufficiently satisfied, and to simultaneously use the results of OCTs in a selection index. This, however, could be interpreted as breeding unmotivated or apathetic pigs instead of pigs that better cope with their situation, and should therefore be evaluated well.

\section{Weighting of needs in a breeding goal}

Depending on the kind of pigs and the environment and on societal circumstances in which they are generally kept, some needs will be considered more important or relevant than others while certain needs may even be neglected (for example because they are already sufficiently satisfied or can easily be satisfied by improving the environment). Further, if it is to be expected that for particular needs satisfaction will be more difficult under future environments, then those needs should get extra attention in the breeding programme. In practice, however, genetic selection of pigs will not only focus on welfare aspects but (still) also on (re)production characteristics. This means that only the most important needs, for which fulfilment by adapting the environment is difficult or expensive, will be included in an overall breeding goal by some sort of mutual weighting of the separate pig needs and production traits. Such weighting of welfare traits is basically an ethical issue, but is also part of societal and economical considerations. Olesen et al. (2000) suggest some possibilities to combine market and non-market (or societal) values into one breeding goal.

\section{Including welfare in the selection routine}

Because welfare in terms of animal feelings cannot be measured directly, selection should be based on genetically associated traits, routinely measured on each candidate parent and/or its relatives. As shown in Figure 2, such traits can be classified at three levels: C-values (see Figure 1), results of various behavioural tests, and the more readily available (coping) traits. Theoretically, C-values are to be preferred because of their assumed, but still to be tested, high genetic correlation with animal feelings. However, obtaining C-values requires stepwise changing of environmental test conditions for each relevant need according to pre-tested protocols and meanwhile measuring the behavioural and physiological responses of each animal. Although we think that this is achievable in test stations by testing sibs for at least some needs, it may look unattractive to pig breeding organizations because of high testing 
costs. A cheaper and more practical alternative is to test the candidate breeding pigs under one set of constant but relatively hard conditions, with respect to the important needs, and select those animals with no or the least aberrant behavioural and physiological reactions. This is in fact similar to using level-3 traits in Figure 2, but measured under special conditions. Measuring level-3 traits corresponds to McGlone (2001) stating that a multidisciplinary approach should be used to evaluate animal welfare, based on a combination of level of productivity, behaviour, physiology, anatomy and health and immunity. This approach also includes traits that are already used in present pig breeding like leg quality, disease incidences and survival rate, which besides in station tests can also be recorded in 'on-the-farm tests'.

In case C-values cannot be obtained, we propose that pig breeding organizations start to routinely measure level-3 traits under test-station conditions that considerably challenge pigs' coping mechanisms, and under standard conditions on farms. This implies in fact measuring the success rates of pigs to cope with the environmental conditions in order to reinforce natural coping mechanisms by genetic selection. This should result in a decrease in the numbers of animals showing aberrant behaviour or diseases, both aspects perceived by the society as being most related to animal welfare (and in the end it is the public's perception that will drive the issue, to quote McGlone, 2001). In addition, before or after the normal test period the amount of work a pig is willing to do to obtain a better environment in different OCTs could be measured (e.g. Sørensen et al., 2001) and other behavioural tests (e.g. van Erpvan der Kooij et al., 2002) could be carried out, and these level-2 test results could be used to increase selection accuracy.

An important problem with the inclusion of any new trait in breeding programs is the lack of knowledge on its phenotypic and genetic parameters. This is not only the case for the C-values derived from the presented concept, but holds for most other welfarerelated traits. To facilitate estimation of these parameters, accurate definitions of the traits involved and the collection of proper data are required. This may take several years; in the meantime selection for welfare can only be based on guessed parameters that should be improved gradually.

\section{Consequences of selection for welfare}

Selection for one trait might affect other traits. For example, Rauw et al. (1998) showed significant negative genetic correlations between leg quality and lean meat percentage or daily growth rate of pigs.
Grandin and Deesing (1998b) suggest unfavourable genetic correlations between lean meat percentage and stress susceptibility, even in pig populations free from the halothane allele, and Hemsworth et al. (1989) found strong negative (but phenotypic) correlations between fear of humans and reproductive performance. Therefore, selection for (re)production traits possibly has resulted in pigs for which welfare is more at risk. In terms of the model in Figure 1, their acceptable welfare zone (C1 to C4) may be shorter. As indicated by Rauw et al. (1998) a further genetic decline of welfare can be stopped by incorporating welfare traits in the breeding goal, with the likely consequence that genetic progress for production traits will decline to some degree.

It can also be imagined that (strong) selection for some welfare traits has undesired consequences for other welfare traits or (re)production traits. For example, selecting pigs with a lower explorative need could eventually lead to a decrease in voluntary food intake, or selection against the pre-partum nestbuilding need could result in pigs with little or no oestrus behaviour. It is important to be aware of such possible undesired correlated effects and to account for them. Therefore, research must be encouraged to study the physiological relationships among the traits involved and to estimate the necessary phenotypic and genetic parameters in order to be able to develop a breeding programme with a good balance between pig production traits and welfare traits.

Another risk of breeding pigs that better tolerate worse environmental conditions or a larger range of environmental conditions, is that pig farmers may tend to pay less attention to optimizing these conditions. As also stated by Faure and Mills (1998) genetic selection should be used as one method to improve welfare, without neglecting other methods. Therefore, regulations that set minimum requirements for housing and management of pigs are still needed. Selection for better welfare within such a framework can guarantee sufficient welfare if the minimum requirements are just met or even if, by chance, they are not met.

\section{Ethics of breeding for welfare}

Animal breeding more and more seems to become a debatable activity. This is largely due to societal and ethical concerns about recent bio-techniques like genetic modification and cloning. However, discussion about classical quantitative breeding is also increasing because it is mainly aiming at a higher production per animal and may have undesired effects on animal welfare and health. Furthermore, animal breeding may have effects on 
genetic diversity and it often does not fit the ideas many people have about animal integrity. Nevertheless, animal breeding has already been applied for centuries in the process of domestication and it has contributed a lot to the production of human food and human welfare. During the last decades, however, genetic change has been speeded up a lot due to the application of highly structured and efficient breeding programmes, and this genetic progress will probably continue to increase by the continuing use of new (molecular) genetic and computational techniques. This means that possible negative effects, like those on animal welfare and health, became and will continue to become more pronounced as well. On the other hand, existing and new breeding techniques can also be used for a purposive genetic selection for animal welfare and health, first of all to avoid a possible further deterioration but also for a real improvement.

Except for those people who are of the opinion that animal populations should not be changed at all genetically, breeding for better animal welfare looks ethically justifiable. Breeding of pigs that better tolerate the common farm conditions and, for example, do not show stereotypic behaviour in exploratively poor environments or that don't show nest-building behaviour, should not be interpreted as breeding of listless or even apathetic pigs. Although this cannot be excluded, it is more likely that the pigs will be genetically better able to cope with their situation and to habituate to it. Breeding is not aiming at the loss of abnormal coping behaviours but at animals which are able to cope with unfavourable or unfamiliar conditions by normal adaptive behaviour. In this respect, selection for welfare can be considered as a fast means of domestication (see also Newman (1994) for relationships between domestication and selection for improved welfare). Domesticated pigs are better adapted to farm conditions than undomesticated (wild) pigs, because they are less active and less nervous or anxious (Gustafsson et al., 1999; Price, 1999; Ŝpinka et al., 2000). This is not only reflected in their behaviour, but for example also in their lower saliva-cortisol levels in response to various stressors (Schuurman et al., 1997; Ŝpinka et al., 2000). Like adaptations by domestication, the proposed behavioural and physiological changes by genetic selection should not be considered as abnormalities but rather as functional skills that equip pigs with better abilities to cope with their human-made environment. Regarding needs like social contact and health (avoidance of suffering), selection for better welfare will result in robust pigs that have more social skills and a better immune system. Such adaptations are ethically well recommendable.
Conclusions

Welfare of pigs, defined in terms of feelings, is partly genetically determined. Improving welfare by breeding is, therefore, possible. The main practical problem of breeding for better welfare consists of accurately specifying the breeding goal and routinely recording relevant information from each selection candidate and/or its relatives. The present study shows that the existing thermoregulatory model can be extended to develop a conceptual framework that describes a pig's welfare as a function of the farm conditions in which it is kept. Various needs that affect pig welfare fit in this general framework. Based on physiological and behavioural responses of pigs to changing conditions, different welfare zones can be identified and the transition points between these zones (C-values) can serve as breeding-goal traits. However, as long as genetic parameters for these transition points are not available, common welfare-related traits like temperament, stress resistance and robustness are useful alternative breeding-goal traits. To obtain selection-index information, the measurement of C-values on sibs of candidate breeding pigs in test stations is a possibility which also provides data for estimating genetic parameters. A cheaper alternative is to test pigs under hard conditions and select those animals with the least problems associated with coping. Additionally, behavioural (stress) tests could be carried out. On the farm, problems associated with coping like incidences of diseases, injuries, stereotypies, etc. as well as longevity, ease of handling, certain blood parameters and even some production traits could be recorded routinely to select for improved pig welfare.

\section{Acknowledgements}

Comments and discussions by the Green Piggery project team of INRA-WUR on drafts of this paper have been greatly appreciated.

\section{References}

Barnett, J. L., Hemsworth, P. H., Cronin, G. M., Jongman, E. C. and Hutson, G. D. 2001. A review of the welfare issues for sows and piglets in relation to housing. Australian Journal of Agricultural Research 52: 1-28.

Benus, R. F., Bohus, B., Koolhaas, J. M. and Van Oortmerssen, G. A. 1991. Heritable variation for aggression as a reflection of individual coping strategies. Experientia 47: 1008-1019.

Bergeron, R., Bolduc, J., Ramonet, Y., Meunier-Salaün, M. C. and Robert, S. 2000. Feeding motivation and stereotypies in pregnant sows fed increasing levels of fibre and/or food. Applied Animal Behaviour Science 70: 27-40.

Bracke, M. B. M. 2001. Modelling of animal welfare: the development of a decision support system to assess the welfare status of pregnant sows. Ph. D. thesis, Wageningen University. 
Bracke, M. B. M., Spruijt, B. M. and Metz, J. H. M. 1999. Overall animal welfare reviewed. 3. Welfare assessment based on needs and supported by expert opinion. Netherlands Journal of Agricultural Science 47: 307-322.

Brandt, H. and Täubert, H. 1998. Parameter estimates for purebred and crossbred performances in pigs. Journal of Animal Breeding and Genetics 115: 97-104.

Broom, D. M. 1994. The effects of production efficiency on animal welfare. In Biological basis of sustainable animal production. (ed. E. A. Huisman, J. W. M. Osse, D. van der Heide, S. Tamminga, B. J. Tolkamp, W. G. P. Schouten, C. E. Hollingworth and G. L. van Winkel), proceedings of the fouth Zodiac symposium, EAAP publication no. 67, pp. 201-211. Wageningen Press, Wageningen.

Brown-Brandl, T. M., Eigenberg, R. A., Nienaber, J. A. and Kachman, S.D. 2001. Thermoregulatory profile of a newer genetic line of pigs. Livestock Production Science 71: 253-260.

Craig, J. V. and Muir, W. M. 1989. Fearful and associated responses of caged white leghorn hens: genetic parameter estimates. Poultry Science 68: 1040-1046.

Cronin, G. M., Wiepkema, P. R. and Van Ree, J. M. 1985. Endogenous opioids are involved in abnormal stereotyped behaviours of tethered sows. Neuropeptides 6: 527-530.

Dellmeier, G. R. 1989. Motivation in relation to the welfare of enclosed livestock. Applied Animal Behaviour Science 22: 129-138.

Eissen, J. J., Kanis, E. and Kemp, B. 2000. Sow factors affecting voluntary feed intake during lactation. Livestock Production Science 64: 147-165.

Erp-van der Kooij, van, E., Kuijpers, A. H., Schrama, J. W., Eerdenburg, F. J. C. M. van, Schouten, W. G. P. and Tielen, M. J. M. 2002. Can we predict behaviour in pigs? Searching for consistency in behaviour over time and across situations. Applied Animal Behaviour Science 75: 293-305.

Faure, J. M. and Mills, A. D. 1998. Improving the adaptability of animals by selection. In Genetics and the behavior of domestic animals (ed. T. Grandin), pp. 235-264. Academic Press, San Diego.

Geers, R., Bleus, E., Van Schie, T., Villé, H., Gerard, H., Janssens, S., Nackaerts, G., Decuypere, E. and Jourquin, J. 1994. Transport of pigs different with respect to the halothane gene: stress assessment. Journal of Animal Science 72: 2552-2558.

Grandin, T. and Deesing, M. J. 1998a. Behavioral genetics and animal science. In Genetics and the behavior of domestic animals (ed. T. Grandin), pp. 1-30. Academic Press, San Diego.

Grandin, T. and Deesing, M. J. 1998b. Genetics and animal welfare. In Genetics and the behavior of domestic animals (ed. T. Grandin), pp. 319-346. Academic Press, San Diego.

Gustafsson, M., Jensen, P., Jonge, F. H. de and Schuurman, T. 1999. Domestication effects on foraging strategies in pigs (Sus scrofa). Applied Animal Behaviour Science 62: 305-317.

Hemsworth, P. H., Barnett, J. L., Coleman, G. J. and Hansen, C. 1989. A study on the relationships between the attitudinal and behavioural profiles of stockpersons and the level of fear of humans and reproductive performance of commercial pigs. Applied Animal Behaviour Science 23: 301-314.
Hemsworth, P. H., Barnett, J. L., Treacy, D. and Madgwick, P. 1990. The heritability of the trait fear of humans and the association between this trait and subsequent reproductive performance of gilts. Applied Animal Behaviour Science 25: 85-95.

Henryon, M., Berg, P., Jensen, J. and Andersen, S. 2001. Genetic variation for resistance to clinical and subclinical diseases exists in growing pigs. Animal Science 73: 375-387.

Hermesch, S., Luxford, B. D. and Graser, H. -U. 2000. Genetic parameters for lean meat yield, meat quality, reproduction and feed efficiency traits for Australian pigs. 1. Description of traits and heritability estimates. Livestock Production Science 65: 239-248.

Jensen, P. and Toates, F. M. 1997. Stress as a state of motivational systems. Applied Animal Behaviour Science 53: 145-156.

Jones, R. B. and Hocking, P. M. 1999. Genetic selection for poultry behaviour: big bad wolf or friend in need? Animal Welfare 8: 343-359.

Kanis, E., Groen, A. F. and Greef, K. H. de. 2003. Societal concerns about pork and pork production and their relationships to the production system. Journal of Agricultural and Environmental Ethics 16: 137-162.

Kjaer, J. B. and Sørensen, P. 1997. Feather pecking behaviour in White Leghorns, a genetic study. British Poultry Science 38: 333-341.

Kjaer, J. B., Sørensen, P. and Su, G. 2001. Divergent selection on feather pecking behaviour in laying hens (Gallus gallus domesticus). Applied Animal Behaviour Science 71: 229-239.

Le Bellego, L., Milgen, J. van and Noblet, J. 2002. Effect of high temperature and low-protein diets on the performance of growing-finishing pigs. Journal of Animal Science 80: 691-701.

McGlone, J. J. 2001. Farm animal welfare in the context of other society issues: toward sustainable systems. Livestock Production Science 72: 75-81.

Mitlöhner, F. M., Morrow, J. L., Dailey, J. W., Wilson, S. C., Galyean, M. L., Miller, M. F. and McGlone, J. J. 2001. Shade and water misting effects on behavior, physiology, performance, and carcass traits of heat-stressed feedlot cattle. Journal of Animal Science 79: 2327-2335.

Mount, L. E. 1979. Adaptation to thermal environment: man and his productive animals. Edward Arnold (Publishers) Ltd, London.

Muir, W. M. 1996. Group selection for adaptation to multiple-hen cages: selection program and direct responses. Poultry Science 75: 447-458.

Muir, W. M. and Schinckel, A. 2002. Incorporation of competitive effects in breeding programs to improve productivity and animal well being. Proceedings of the seventh world congress on genetics applied to livestock production, Montpellier, communication no. 14-07.

Newman, S. 1994. Quantitative and molecular-genetic effects on animal well-being: adaptive mechanisms. Journal of Animal Science 72: 1641-1653.

Olesen, I., Groen, A. F. and Gjerde, B. 2000. Definition of breeding goals for sustainable production systems. Journal of Animal Science 78: 570-582. 
Price, E. O. 1999. Behavioural development in animals undergoing domestication. Applied Animal Behaviour Science 65: 245-271.

Rauw, W. M., Kanis, E., Noordhuizen-Stassen, E. N. and Grommers, F. J. 1998. Undesirable side effects of selection for high production efficiency in farm animals: a review. Livestock Production Science 56: 15-33.

Rowan, A. N. 1997. The concepts of animal welfare and animal suffering. In Animal alternatives, welfare and ethics. (ed. L. F. M. van Zutphen and M. Balls), proceedings of the second world congress on alternatives and animal use in the life sciences, pp. 157-168. Elsevier, Amsterdam.

Sandøe, P., Nielsen, B. L., Christensen, L. G. and Sørensen, P. 1999. Staying good while playing God - the ethics of breeding farm animals. Animal Welfare 8: 313-328.

Schaeffer, A. L., Sather, A. P., Tong, A. K. W. and Lepace, P. 1989. Behaviour in pigs from three genotypes segregating at the halothane locus. Applied Animal Behaviour Science 23: 15-25.

Schoenecker, B. and Heller, K. E. 2000. Indication of a genetic basis of stereotypies in laboratory-bred bank voles (Clethrionomys glareolus). Applied Animal Behaviour Science 68: 339-347.

Schutz, M. M. and Pajor, E. A. 2001. Genetic control of dairy cattle behavior. Journal of Dairy Science 84: (suppl. ) E31-E38.

Schuurman, T., Wichers Schreur, M. J. M., Olsson, A. and De Jonge, F. H. 1997. Behavioural and physiological differences between domesticated and crossbred pigs: effects of domestication. Proceedings of the 31st international congress of the ISAE, Prague, Czech Republic (ed. P. H. Hemsworth, M. Spinka and L'. Koŝt'ál), pp. 113-114. Polygrafia SAV, Slovakia.

Schwaibold, U. and Pillay, N. 2001. Stereotypic behaviour is genetically transmitted in the African striped mouse Rhabdomys pumilio. Applied Animal Behaviour Science 74: 273-280.
Scientific Veterinary Committee. 1997. The welfare of intensively kept pigs. EU-Doc XXIV/B3/ScVC/0005/1997, http : //europa. eu. int/comm/food/fs/sc/oldcomm4/ out17_en. html

Scobie, D. R., Bray, A. R. and O'Connell, D. 1999. A breeding goal to improve the welfare of sheep. Animal Welfare 8: 391-406.

Sørensen, D. B., Ladewig, J., Matthews, L., Ersbøll, A. K. and Lawson, L. 2001. Measuring motivation: using the cross point of two demand functions as an assessment of the substitutability of two reinforcers. Applied Animal Behaviour Science 74: 281-291.

Ŝpinka, M., Illmann, G., De Jonge, F., Andersson, M., Schuurman, T. and Jensen, P. 2000. Dimensions of maternal behaviour characteristics in domestic and wild $\times$ domestic crossbred sows. Applied Animal Behaviour Science 70: 99-114.

Verstegen, M. W. A. and Close, W. H. 1994. The environment and the growing pig. In Principles of pig science (ed. D. J. A. Cole, J. Wiseman and M. A. Varley), pp. 333-353. Nottingham University Press, Nottingham.

Wechsler, B. 1995 . Coping and coping strategies: a behavioural view. Applied Animal Behaviour Science 43: 123-134.

Wiepkema, P. R. 1987. Behavioural aspects of stress. In Biology of stress in farm animals: an integrative approach (ed. P. R. Wiepkema and P. W. M. van Adrichem), pp. 113-133. Martinus Nijhoff, Dordrecht.

Wilkie, B. and Mallard, B. 1999. Selection for high immune response: an alternative approach to animal health maintenance? Veterinary Immunology and Immunopathology 72: 231-235.

Yazdi, M. H., Rydhmer, L., Ringmar-Cederberg, E., Lundeheim, N. and Johansson, K. 2000. Genetic study of longevity in Swedish Landrace sows. Livestock Production Science 63: 255-264.

(Received 26 February 2002-Accepted 25 October 2003) 